\title{
Customs Risk Management in Albania. An important Step towards Integration in the European Union
}

\author{
Ejona Bardhi ${ }^{1}$
}

\begin{abstract}
The customs are involved within the state administration; they are responsible in collecting the customs liabilities as well as for the international flux of goods. This responsibility is provided in the national legislation and in the international rules of trade. The customs are a unique body, among all the state bodies due to the fact that they have the position of both national and international agency. They are positioned at the international borders not only as an expression of the sovranity of a country but as well as national guard against all the external threats against health, security, environment and domestic industry. Te importance of the customs is increasing due to the increase of international trade as well as of the increasing request on security. The customs administration is reviewing all the operations towards the international standards and best practices to realize a suitable customs administration which would lead in easing the international trade. The importance of customs procedural requests is increasing as a consequence of the increase of the international trade during the latest years. The increase of customs procedural requests increased adding the costs of government, business and consummators. The customs are responsible for achieving the competitive objectives, as well as for controlling the borders and offering facilitations in international legal trade. The facilitation of the trade through the diminution of customs payments, is important in economies in development and in the developed ones, due to the contribute in exports growth, in improving the concurrence of goods and services at the global market, in attracting more IHD-s, in increasing the participation of small and medium enterprises at the international market. The customs are responsible for the facilitation of trade, for this reason they are in continuous process of reformation and modernization in the under development and developed countries. Due the rules based at the trade policies of WTO, it was made possible that the fees were decreased and non-fee barriers are in cancelations. The customs administration is excepted to bring incomes, to stop the import of not safe or banned goods and to the fight the narcotics trade. It is excepted to fulfill these targets effectively without hamper the commercial facilitations. This paper has as the main objective to treat the management of risk at the customs. During this paper I will treat the main problematic of the customs administrations in Europe and Albania, including theory and practice aspects. This paper treats: controls after the passing permission at the Customs, levels of risk management, costs and benefits of the techniques of risk management, management of facilitation and customs activity, the importance of information of customs system, important problematic in customs activity, rule of origin and its importance and finally the transit as the main mean of trade facilitation.
\end{abstract}

Keywords: Management, risk, customs, administration, trade

\section{Risk Management at the Customs}

The risk of a custom body is the possibility of happening of the events or actions which can cause obstacles in obtaining the targets. One of the main functions of the customs is to assure the trade facilitation during the customs procedures, for the local and foreign businesses. The activity of these businesses must be in accordance with the laws and rules of the country. The 
control of the respecting these rules and laws and the discovery of the violations during the international trade is another function of the customs. This is a very important function, as it is assured the control of payment of all the customs liabilities.

The risk that the customs have includes: firstly, the possibility of non-compliance with customs laws; the required licenses, value of supply, rule of origin, regime of exclusion from liabilities, limitations in trading, rules of security and secondly, the possibility of failures of customs in facilitating the international trade.

The customs as every other body need to manage their risk. This requires systematical procedures which are necessary in decreasing the risk, assuring that the appointed targets are effectively met. these procedures include: identification, analyze, evaluation, treatment, monitoring and review of the risk, which can violate the achievement of objectives.

The risk management at the customs is fundamental in effective customs operations, and it must be highlighted that the customs administration applies everywhere certain forms of risk management, formal and informal ones. Based on the previous experiences and on the information, the customs have always applied necessary procedures to identify illegal activities, while attempting to decrease the risk. The most traditional procedures include physical and documentation control of persons in order to trace the banned trade. Such controls constitute a form of risk management, but not necessarily the most effective one.

The volume of foreign trade has increased. Also its complexity and speed has increased, and this was helped by the continuous development of technology. If every shipment was controlled, the queue at the customs would always be present, creating delays and corruption. As a consequence, the customs administration is expected to implement more means of risk management. This with impact not only in increasing the efficiency but also in minimization of interference during the trade transactions decreasing in this way the non-fee barriers in trade.

\section{The Separation of Shipment Control from the Procedures of Granting Permission}

A traditional feature of the work at the customs is the big volume of transaction and the impossibility to control all the transactions. The customs administration is faced with the challenge of facilitating the movement of passengers and shipment, while they have to perform the controls in order to avoid possible dangers. The customs service is always under the pressure of national governments as well as of the international organizations, to facilitate the passing of passengers and goods, while the pressure to avoid different dangers is increased.

The purpose of customs controls, is to assure all the people, means and goods that pass at the customs borders in accordance with the legal system, rules and customs procedures of passing at the border in accordance with the legal system, rules and customs procedures of passing at the border in a short time.

The customs controls may be classified in three levels: before the permission of border passing, during the border passing and customs controls after the border passing or latter audit. These controls are focused at identifying the risk that seriously impact the applications of customs rules and procedures as well as considering of several customs controls which define the possible failures, as well as the indexes of risk which may increase or decrease its level.

The indexes of risk are connected to the codes of goods, their origin, value, mass, licenses etc. the elements in defying the risk will include: samples of imports, tax and liabilities level, type of the goods, results of the previous examination as well as the manner and way of transportation.

The selective inspection will include the analysis of declaration of data and selection of the shipments based on the risk parameters or at the preliminary evaluation criteria according to the possible risk that may be involved a goods sender. Starting from the definition of the level of risk the products pass through these channels: green channel, where the products pass without no 
examination, yellow channel, where the products are not physically examined but all their documentation is checked, red channel where the products are physically examined and their relevant documentation is examined and blue channel, where the control is examined at a latter phase, the latter audit.

The techniques of risk management permit the travellers and shipments with low risk to pass with minimal interference at the customs and to circulate fast.

At the situation with high risk there will be special attention in comparison to the situation with low risk, minimizing the risk of possibility of customs violations. This requires the necessary capacities which constitute the cost of risk management against the benefit of non-violating the laws.

An alternative of risk management with limited capacities is the control at the moment of arrival at the customs expressing that this will be enough to discover the violations. In every case the control by selection is better and this type of management of risk is more efficient and improves the chances of discovering the violations.

The customs controls are based at the risk management, decrease the need for controls which results in saved direct cost for the private sector at 1 million dollar per month (WTO, Symposium on Trade Facilitation, March 1998).

The division of control from granting the permission may be described as a procedure that allows the goods to be free from customs procedures, before the payment of liabilities and taxes. In this case the final determination of goods classification, the determination of their value and other transactions are postponed in time.

The division of controls from movement is important, at a time when it is required to have a quick movement. When the goods classification may difficult to be determined in time, such as for the chemical products, which require laboratory analysis. All this would cause delays in putting the goods in market decreasing their concurrence.

The delays in this phase are due to several reasons for example the lack of adequate information to determine the goods classification, goods value, the right fee or lack of documentation. To perform the division between the movement and controls. It is important a warranty from businesses for the procedures that perform.

So for example, the problems of customs evaluation are important as the value and direct costs form the basic value where all the liabilities and taxes are applied. A fee may be absent, a sales may be not based in documentation or the customs may require further data to verify the declared value. So, for example, the exports that come when the exporting firm is a branch of importing firm or they have other connections between them are very difficult. These situations are solved with experts or other defined methods, but it is sure that all these cause delays in putting the goods into market. This is a situations which is solved upon warranties enough to cover the payments towards the customs.

\subsection{Granting the permission of customs passing before the arrival of the shipment.}

Upon the application of granting the permission before the arrival of the shipment in the customs, the traders or other representatives may pass the charge with little or no delay. So, this a function which allows the traders to submit the shipment data before its arrival and to pass it immediately. The permission may be granted in advance if the customs communicate it with the necessary details.

Granting the permission of customs passing before the arrival of the shipment is a measure that facilitates the trade connected to the article VIII of GATT, 1994. This summarizes the need for minimizing the formalities, complexity of export and import, as well as facilitation and diminution of necessary documentation.

According to the OBD there are several categories of goods for which it can be moved in 
advanced such as for the ones which have documentation with no commercial value, small value where no tax are paid. The shipment with small value of liabilities as well as the charge with high value and taxes are assured through warranties.

A special role at this procedure is occupied by the information system, through which the traders send to the customs shipment data. In this way the customs may perform the control of documentation and the determination of the channel they will pass through.

\subsection{Controls after the permission of passing at the customs}

These controls mean that the customs controls or audits will be performed after the shipments pass the customs. These controls may be performed for special transactions or for transactions which cover import/export for a certain time. The application of the control after the passing is one of the facilitations of customs controls. These controls may be performed both at the customs or at the enterprises. The application of the control after the passing is one of the facilitations of the customs controls and offers facilitation in moving the shipments and the traders get their goods at the moment they arrive.

Traditionally, the customs procedures are applied upon the arrival of the goods in border or port and the goods are placed at a customs store waiting that their legal representative submits the customs declaration and supporting documents at the customs office. The process of movement may last several days or weeks if there are irregularities. Nevertheless, the goods are under the customs security until everything is solved, including the payment of liabilities and taxes.

Applying the techniques of risk management and control after the movement, the customs are able to move a big part of shipments and retain only those shipments which are doubted to have risk. The shipments with no doubts are moved immediately and may be controlled latter these controls are based on supporting documentations such as account books, registrations and surveillance at the importing company.

The control of goods after movement is more efficient than the traditional control being that the latter are performed without having a clear target of what they are controlling but they simply determine if everything is all right. While the controls after the movement are based on the analysis of the available documentation on the import and their companies.

The adequate systems of information allow controls based on the local, national and international data, comparing the goods with the identical ones and through the comparison of prices or applied fees, it is easier that contraband is caught. After this action the reevaluation of goods would lead in higher taxes and liabilities and consequently the controls after the movement would bring more incomes for the customs.

Changing the traditional controls, the pressure of the traders towards the officers of the customs is decreased. In this way the customs administration has more time to plan and rank the shipments it has to control. The later control is one of the best ways to facilitate trade, considering that they may pass with no customs interference to 80 or $90 \%$ of imports. At our country this forms exist through the activities of teams in movement and inspections during the road or customs stores, but it is not enough and it must be improved.

The Albanian customs are mainly focused at the physical inspection of goods at the border. This kind of inspection has great efficiency in security and has a positive impact in verification of the goods quantity, but is less effective in verifying the classification of goods for the effect of fees, origin control, evaluations and exclusions from liabilities.

The performance of the control after the movement is more efficient for the fact that in this way the payments the businesses had to make for goods storage are saved. 


\section{Levels of Risk Management}

The risk management at the customs must be performed on three levels: at the strategic level, where the risky areas are determined: collection of taxes and other liabilities, removal of the obstacles for import/export, measures for health security. Risk analysis ranks several fields of risk which is important to assure necessary information for the lower levels of risk management.

At the operational level, the necessary level of control for the risk management must be determined for a certain purpose at the customs. In this way the customs administration changes from a general monitoring at a service which acts selectively during the customs procedures, interfering only in case of doubt for a high level of risk.

At the Tactical level, where the customs officers put in practice the risk management in concrete situation. They use their knowledge, experience and defined regulations to determine which charges have higher risk and they exercise control over them.

The selection, profiling, targeting are three aspects of risk management. The criteria of selection of goods to be allowed to enter the territory includes the history of the importer and exporter, transport mean, representative agent, origin of the good, transport ways and other measures towards the imported or exported goods. The indexes of the risk are defined at the criteria of selection such as product type, origin rule, value, company, type of transporting mean, reason why the goods are entering the customs territory etc.

The risk profile is a result of the analysis of risk and is the documentation of the customs authorities that involve details of risk in several situations. Its purpose is to substitute the full control of all goods that pass the border upon inspection in accordance with the individual risk that each charge has. In order to evaluate the risk level a large number of resources may be used such as: origin country (if the good is not produced at the declared country, seals and certificates of origin are doubtful; the country of origin is different from the country where the good is imported; the receiver has a history of violations; the description of the goods in not full and with mistakes). Other cases where it may be considered with risk, are when at the invoice there are lack of data tel/fax, email, addresses, and number of fiscal register, the payment method is in cash or advance, not printed documentation etc.

In this way the customs authorities may analyze the risk and determine what is the shipment or mean to be controlled and the level of control. For example, for the authorized legal representatives who meet the customs requirements, that include the accordance with the customs regulations and regular accounting registers, the customs may allow that the goods pass with minimal information just to identify them upon a customs declaration, when a business frequently performs imports or exports for a certain time as well as to use the registrations of the authorized person on the calculation of customs liabilities etc.

Meanwhile the persons who at the past were caught with violations of rules must be treated more strictly than the previous violations.

\subsection{Costs and benefit of the techniques of risk management.}

The techniques of risk management provide the reconstruction of customs resources to perform the controls in where high and unknown risks are identified. Also to improve the efficiency and productivity of the customs these techniques decrease the unnecessary liabilities in trade lowering the level of physical inspection, narrow points during the border passing and substitute several controls of documentation upon audit after the border passing. They increase the predictability and sustainability of the requests of customs, allowing the harmonization of practices between different customs points and facilitation of information division.

The decrease of controls may be applied in shipments with low value for which the detailed 
control is unnecessary and which are not object to important customs shipments. Also, the need for physical inspection may be decreased for the transit markets excluding the fact that it must be assured that the goods are the same to what it was declared and that with pass the country territory, as they entered, without selling at a illegal way.

\subsubsection{Benefits of techniques of risk management.}

Better allocation of buman resources. Following the implementation of the method based on the risk for permission of passing, the customs management may improve the staff level from a work force that generated high results, to a work with high quality directed in the improvement of the results of examinations and controls.

Increase of incomes. Nevertheless the low level of examination, the improvement of efficiency and professionalism at the customs results in increase of collected liabilities at the customs.

Improves the accordance between the law and regulations. There exist a lot of experiences where the improvement of efficiency at the customs with the desire of the traders for a quick pass through the green channel brings better respecting of the laws from the traders.

Improves the collaboration through the traders, this is part of the process of determination of the risk fro the products which are transported or for import/export specialized according to the traders. The contacts and communication between them would improve the relations at a general level. It is very desirable that the relationship of partnership between the customs and traders (BB)

The time of movement is lowered. Only 10-20 percent of the goods are examined under the movement based on the risk. The customs may be focused in this small part of import and to move all the big part of shipments immediately upon the submission of the permission of passing.

Lower cost of transaction. The time of movement of the products at the customs using the old procedures ways is from 1 to 2 weeks, at our customs the average time of movement in export and import is 10 days. The new techniques of management will move $80-90$ percent of the goods, in few hours and will save considerable costs for the traders.

\subsubsection{Costs of techniques of risk management}

The calculation of risk may mean important changes at the infrastructure of an administration. For example it will be needed a national and international intelligence structure which means less officers for the goods control and documentation control and more audits and investigators. Assuring an automatized system at the customs for the procedures and administration of risk management, it is necessary an intelligent database and the increased of some computer screens. Also, the introduction of the new technology requires additional trainings of staff to be involved.

\section{Management of Facilitation and Control}

As it was highlighted up supra , the two key objectives of the customs are "facilitation" and "control". Requiring to achieve the equilliber between the facilitation of trade and the legal control, the customs may manage two risk: the potential failure in facilitation of the international trade and possible discordance with the customs laws. Often it is supposed that upon the increase of the level of trade facilitation, the control level would decrease, as when the control is higher the trade is damaged.

There exists some points of view which support the fact that the only way to facilitate the movement of goods at the customs is to lower the control level. There cannot be claimed for facilitation in damage of the control or the contrary as these two objectives are part of continuity. For these reasons I presented these two objectives as two variables at the following matrices: 


\section{Control \\ $\mathrm{HIGH}$ \\ LOW}

\section{FACILITATION}

The upper left quadrate (high control, low facilitation) represents a customs regime with high control where the customs requirements are at a severe level, damaging the facilitation of the trade. This style of managing risk, where the customs play the role of national guard applies in this way the methods of risk contradiction. This method is often criticized by the modern societies, as when the society expects increase of the trade and benefits, the customs interference must be minimized.

The lower left quadrate (low control, low facilitation) describes a customs administration in full managerial crises, which not only exercises a low control but also does not do anything for the facilitation. Neither the government nor the community benefit from this situation.

The lower right quadrate (low control, low facilitation) represents a management way there the facilitation of the trade is very important for the customs. But the control is in low levels. This is a management way for an ideal world where the trade community acts with no risk. The re exist no interference form the government because there exist no risk.

The forth quadrate, up right (low control, high facilitation) represents the equiliber between the two objects of control and facilitation, as they are both in high levels. This management level maximizes the benefits for the customs and for the international trade. This is the management level that every customs administration should try to achieve including the Albanian one.

The effective application of the principle of the risk management is important in achieving the equiliber between the control and facilitation. Only when the risk management is effective, so more sophisticated and systematical, there will be a good equillber between the control and facilitation. So those administrations which are able to achieve high level of control and facilitation, make this possible through an effective risk management. The administrations in management crisis are adapting a strategy where the risk management is absent.

Although, every attempt to exit from the managerial crisis, shows the existence of a form of risk management. For example, if there is discovered that there exists the possibility that a certain risk may affect the achievement of customs targets, a regulatory strategy that achieves a kind of control, even a small one, represents a methods that treats possible violations or discordance with the customs law.

As it was mentioned up supra, the role of customs is to control the law respecting so to assure the trade facilitation. Comparing the managerial style of national guard, where there are controls are performed 100 percent, with the managerial style of risk management, at the first the payments of customs liabilities and other taxes are a pre-condition to allow goods to pass. This passing of the goods would be refused until all the formalities are completed. At the second style, the regions where risky products may come would have importance, addressing the resources towards all these shipments and the control would be minimal for the shipment with low risk. This type of strategy disconnects the connection between the physical control of goods and the payment of obligations and grants the permission of passing the shipments before they arrive.

The position of the customs administration in each quadrate of the matrices id defined by several categories such as:

- Country legislation

- Structure of customs administrate

- Type of risk management applied at the customs administration

- Existence of necessary technology for adapting the risk management.

This four categories represent the elements that define the way of movement of the shipment during the customs passing and the manner of control exercised on this shipment. 
The legislation must contain the necessary legal basis that allows the application of several administrative strategies and management risk that an administration chooses to follow. For example, there must exist the necessary legal space to divide the procedures of physical control from the collection of liabilities that are traditionally collected at the customs.

The legislation is with no doubt the support of other categories such as of the elements of customs administrative structure as well as of the adapted risk management structure. The structure of the latter reflects in an essential way the managerial style, which at the modern customs is being directed more and more towards the management risk style. The available technology of customs administration provides the facilitation of the achievement of risk management.

\section{Management of Law Respecting}

Firstly, it is important that the business community is able to achieve the requests of the customs procedures. This is achieved through a trust relation and consultative meetings providing to the businesses the necessary means to understand their liabilities and rights.

In practical terms, speaking for a control of legal respecting, we mean the physical and documentary control, audits and investigations. These actions determine if a business is in accordance with eh laws or not. The applied strategies for the discordances may be several, starting from continuous requests of law respecting to the penalties provided by low. While for those who exercise their activity in accordance with the law, the strategy would include facilitated controls, knowledge of the evaluations made by the business, agreements on periodic payments and increase of facilitation level at the customs.

Regarding the measures mentioned in case of violations a distinguishing must be done between the indented and not indented violation. In case of the intended violation administrative penalties, prosecution or license removal are necessary. If there was no purpose, for example it came from the lack of controls within the company, or faults at the procedural system seminars and explanatory pamphlets may be prepared.

\section{Management of Facilitation}

More and more, the facilitation of customs procedures is being emergent as a consequence of development of international trade and signature of bilateral and multilateral agreements. During the development of the managerial strategies it is import to consider the basic principle of the Reviewed Convention of Kyoto, according to which the customs must limit the controls only in what is necessary to assure, in order that very thing is in compliance with the law. The administration must be simple and practical as well, decreasing the cost of businesses. According to the World Trade Organization, the facilitation of trade is a harmonization of procedures of international trade. A special attention must be paid to the trade facilitation. The trade procedures involve "activities, practices and formalities regarding the accumulation, communication and processing of the data required for the movement of the goods at the international trade.

The control of documentation for the verification of the legislation urges the facilitation of the trade in comparison to the physical control at the same way the controls after the customs passing represent a method of further facilitation in comparison to the control undertaken at the import moment. This method requires necessary capacity to be successfully adapted, especially at the information of the procedure system. 


\section{Conclusions}

From all this theoretical and practical treatise on risk management in the customs deduce that for the realization of the main functions that management is a constitutive element of the better functioning of customs. There are factors that affect the customs legislation, administrative structures, techniques used for managing risk and proper information system. While there are ongoing problems and violations related to the valuation of prices of goods in customs, in the determination of origin of goods transit procedures, the long time of customs procedures, we can say that risk management is not at the right level and Albania also still working to realize to achieve European standards in customs.

\section{References}

A global market place for consumers: simplifying custons clearance producer. OECD 1999

Artikulli VIII I GATT 1994

Albania 2007 Trade report. USAID, ACIT, ISB

Bardhan 2006, "Corruption and decentralization of Infrastructure Delivery in Developing Countries".

Kodi Doganor I R.SH

Korrupsioni ne R.SH, Sondazhi 2008. Pergatitur nga IDRA

Lehtesimi I proçedurave doganore dhe I marredhenieve te biznesit me administraten doganore, ACIT, 2004

The World Bank, Doing Business in Albania, 2008

www.minfin.gov.al

www.gogana.gov.al

www.tatime.gov.al

www.oecd.org 
